\title{
BMJ Open Quality Is virtual clinic follow-up of hip and knee joint replacement acceptable to patients and clinicians? A sequential mixed methods evaluation
}

\author{
Rebekah J Parkes, ${ }^{1}$ Joanne Palmer, ${ }^{2}$ Jennifer Wingham, ${ }^{3}$ Dan H Williams ${ }^{1}$
}

To cite: Parkes RJ, Palmer J, Wingham J, et al. Is virtual clinic follow-up of hip and knee joint replacement acceptable to patients and clinicians? A sequential mixed methods evaluation. BMJ Open Quality 2019;8:e000502. doi:10.1136/ bmjoq-2018-000502

- Additional material is published online only. To view please visit the journal online (http://dx.doi.org/10.1136/ bmjoq-2018-000502)

Received 10 August 2018 Revised 16 January 2019 Accepted 29 January 2019

A Check for updates

C Author(s) (or their employer(s)) 2019. Re-use permitted under CC BY-NC. No commercial re-use. See rights and permissions. Published by BMJ.

${ }^{1}$ Orthopaedic Department, Royal Cornwall Hospitals NHS Trust, Truro, UK

${ }^{2}$ Academic Vascular Surgical Department, Hull Royal Infirmary Postgraduate Medical Education Centre, Hull, UK

${ }^{3}$ Primary Care Research Group, Institute of Health Research, University of Exeter - Saint Lukes Campus, Exeter, UK

Correspondence to

Rebekah J Parkes;

r.j.parkes@smd14.qmul.ac.uk

\section{ABSTRACT}

Objective To evaluate the acceptability to key stake holders of a newly introduced virtual clinic follow-up pathway for hip and knee joint replacement.

Design A service evaluation comprising a questionnaire sent electronically to 115 patients and interviews with 10 individuals.

Setting A newly introduced virtual clinic follow-up pathway for hip and knee replacement patients in a district general hospital.

Participants The electronic questionnaire was distributed to all patients treated under the virtual clinic service over a 5-month period ( $n=115$ ). Purposive sampling from volunteers among respondents, leading to semi-structured interviews with eight patients. Two orthopaedic consultants were also interviewed.

Intervention Consultant review of web-based patient reported outcome measures and digital radiographs, with feedback to patients via letter, replacing face-to-face outpatient appointments for the follow-up of hip and knee joint replacement.

Results The response rate to the questionnaire was $40 \%$. $44 \%$ indicated they would prefer a virtual appointment over a face-to-face consultation in future. The most common word in the free text comments was 'good' $(n=107)$. Seven main themes were identified from the patient interviews: patient understanding and expectations patient confidence, patient voice, managing deterioration of condition, patient benefit, patient satisfaction using technology and navigating the website. Two main themes were identified from the staff interviews: the adapting patient pathway and project management. Combined analysis elucidated that patients who were doing well liked the 'click and go' approach but those with problems were concerned about how to report these and were therefore less satisfied.

Conclusion The virtual clinic process appears to be well accepted by both patients and clinicians. However, appropriate patient selection and clear pathways of communication to address patient concerns are pivotal to success.

\section{INTRODUCTION}

A total of 101651 hip replacements and 108713 knee replacements were recorded in the UK in 2016 representing an increase of $3.5 \%$ and $3.8 \%$, respectively compared with the previous year. ${ }^{1}$ This increase is reflected globally and is predicted to continue, precipitated by an ageing population and growing rates of obesity. ${ }^{23}$ One projection from the USA estimates increased rates of primary procedures of $174 \%$ and $673 \%$ for hip and knee joint replacements, respectively, between 2005 and 2030. ${ }^{4}$ Cost-effective and efficient follow-up is therefore required to keep pace with demand and to comply with evidence based national guidelines, for example, British Orthopaedic Association (BOA) guidance (see table 1). ${ }^{56}$ The National Institute for Health and Care Excellence are undertaking a consultation to explore the options for monitoring and surveillance, which may not necessarily require face-to-face appointments and can be undertaken remotely with clinicians reviewing radiographs and validated Oxford pain and function scores. ${ }^{17}$

Virtual clinics appear to be gaining popularity and in various forms have been applied across many specialties and contexts but concerns remain around both logistical and technical issues, and acceptability to patients and staff. ${ }^{8}$ In 2014, with support from the Health Foundation (Shine initiative), the orthopaedic team at our district hospital introduced a virtual clinic model for the follow-up of hip and knee joint replacement. Here the acceptability to patients and consultants is evaluated.

\section{PARTICIPANTS AND METHODS}

The clinic

The virtual clinic involved the treating consultant reviewing up-to-date radiographs and the trends in validated patient reported outcome measures (PROMs), using the My Clinical Outcomes (MCO) web-based system, at the intervals set down by the BOA (table 1). ${ }^{910}$

To achieve this the MCO platform is automated to request completion of PROMs by 


\begin{tabular}{|c|c|c|c|}
\hline Patient group & Implant rating & Follow-up timeline & Follow-up content \\
\hline All & All & $\leq 6$ weeks & $\begin{array}{l}\text { Seen and given feedback } \\
\text { about treatment }\end{array}$ \\
\hline Hip replacement $>75$ years & ODEP 10A & \multicolumn{2}{|c|}{ No further routine follow-up required } \\
\hline \multirow[t]{2}{*}{ Hip replacement $<75$ years } & ODEP 10A & $\begin{array}{l}1 \text { year, } 7 \text { years and } 3 \text { yearly } \\
\text { thereafter (if asymptomatic) }\end{array}$ & \multirow{4}{*}{$\begin{array}{l}\text { Telephone or web-basec } \\
\text { PROMs. } \\
\text { Radiographs, reported } \\
\text { by a radiologist with } \\
\text { musculoskeletal interest }\end{array}$} \\
\hline & Novel implants & $\begin{array}{l}\text { Yearly for } 5 \text { years, } 2 \text { yearly until } \\
10 \text { years then } 3 \text { yearly }\end{array}$ & \\
\hline \multirow[t]{2}{*}{ Knee replacement } & Established implants & $\begin{array}{l}1 \text { year, } 7 \text { years and } 3 \text { yearly } \\
\text { thereafter (if asymptomatic) }\end{array}$ & \\
\hline & Novel implants & $\begin{array}{l}\text { Yearly for } 5 \text { years, } 2 \text { yearly until } \\
10 \text { years then } 3 \text { yearly }\end{array}$ & \\
\hline
\end{tabular}

PROMs, patient reported outcome measures. ODEP, orthopaedic data evaluation panel rating

patients at 3-month intervals and patients are also invited to attend for an X-ray appointment at their local hospital.

The outcome of the clinic is relayed to the patient and their general practitioner via letter and can result in ongoing virtual clinic monitoring or recall for face-to-face review.

Patients were recruited to the virtual clinic either preoperatively or at a face-to-face follow-up by the clinical team and were supported in completing the process by an administrator.

\section{The study}

A sequential mixed methods evaluation was performed. Data were collected using a questionnaire followed by semi-structured interviews.

All patients had completed at least one follow-up appointment for their hip or knee joint replacement, using the virtual clinic pathway.

\section{Questionnaire}

The questionnaire was initially piloted being sent to 70 patients, 29 returning responses in a group treated prior to February 2015. It was then administered formally with all patients $(n=115)$ reviewed through the virtual clinic over a 5-month period (February-June 2015) being invited, via email, to complete an online questionnaire (online supplementary appendix 1), using SurveyMonkey, about their experience. ${ }^{11}$ The questionnaire was available online for 1 month. Demographic information was collected and a mixture of Likert-based questions and free text responses were used to assess experience; a final question asked for consent to further contact.

\section{Interviews}

Patients

A sub-sample of eight people (among 15 volunteers) were purposively selected based on age, employment status, education and satisfaction of the virtual clinic experience. The topic guide (online supplementary appendix 2) included questions about expectations of using the virtual clinic, experience of the virtual clinic pathway, what was liked and disliked about the service and any recommendations for future development. All interviews were recorded using an Olympus recording device and transcribed for analysis.

\section{Consultants}

To provide a fuller appreciation of the obstacles and benefits it was felt important to also explore consultants' views. Two out of three consultants approached agreed to audio-recorded face-to-face interview. A topic guide (online supplementary appendix 3) included: experience of the introduction and training on using the virtual clinic web-based platform, expectations and experience of following-up patients using the virtual clinic, barriers and facilitators to using the service, and recommendations for future implementation.

\section{Ethics}

This study was carried out as a service evaluation and therefore did not require formal ethical review.

\section{Data analysis}

A hybrid between explanatory and convergent methods was used. Preliminary results of the questionnaires were used to inform development of the topic card to confirm relevant areas were being discussed and therefore elaborated (explanatory element). However, all three data sources were analysed independently and then combined in a side-by-side joint display (convergent).

All patient data was anonymised and every effort was made to anonymise staff.

The questionnaire results were analysed in Microsoft Excel and NVivo V.12 was also used to perform a word frequency analysis of the free text comments (including stemmed words).

All interviews were transcribed using UK transcription services following a confidentiality agreement. Analysis of the interviews was conducted independently by the two qualitative researchers (JP and JW) and once completed, agreement was reached through discussion. A simple descriptive thematic analysis was performed with each 
transcript read a minimum of three times prior to coding. Extracts of the transcripts were coded; codes with similar meaning were allocated to categories before the final descriptive themes were identified. ${ }^{12}$ This resulted in an overall descriptive thematic synthesis which produced the final overarching themes. The qualitative interview data was treated as the dominant method and the themes were used as domains under which the results of the interviews and questionnaire findings were synthesised (Qual-Quant).

\section{RESULTS}

\section{Online questionnaire}

Of the patients approached $(n=115)$ to give their views of the virtual clinic service, $40 \% \quad(n=46)$ responded to at least part of the online questionnaire. Those responding represented a wide age range (mode 60-70 years). Fifty-one per cent of respondents were male $(\mathrm{n}=18), 31 \%$ $(n=11)$ were in employment and $65 \%(n=23)$ were retired (see table 2 for demographics).

Several patients indicated they had had three or more virtual clinic follow-up appointments which would not have been consistent with the period the clinic had been running raising concern that patients may not be using the same definition as those providing the clinic. Radiographs were undertaken at a variety of hospitals and many indicated they had made savings. The most common free text word was 'good' $(\mathrm{n}=107)$ but several comments indicated a degree of disquiet among some individuals, requiring further elucidation. For full results see online supplementary appendix 4 and figure 1 .

\section{Patient interviews}

In total there were seven interviews conducted face-toface or by telephone, three participants were female, three were male and there was one husband and wife team. The interviews lasted between 8 and 25 min.

The following age categories were represented: 50-60years, $60-70$ years and $70-80$ years. There were two people still in employment with the rest being retired, some participants had undergone formal education such as college or university and one person had not undertaken any further education after leaving school. Seven main themes were identified: patient understanding and expectations, patient confidence, patient voice, managing deterioration of condition, patient benefit, patient satisfaction, using technology and navigating the website. These themes/domains are analysed alongside the other two data sources in table 3.

\section{Clinician interviews}

Two consultant clinicians were interviewed. Two main themes were identified from the data. These are the adapting patient pathway and project management.

Consultants highlighted that prior to the introduction of the virtual clinics, they had autonomy to determine follow-up patterns. They recognised that although this had enabled patient focused practice there may be efficiencies
Table 2 Demographic breakdown of patients responding to online survey

\begin{tabular}{|c|c|c|}
\hline Socio-demographic factor & $\begin{array}{l}\text { Participants } \\
(\mathrm{n}=76)\end{array}$ & Percentage* \\
\hline \multicolumn{3}{|l|}{ Gender } \\
\hline Male & 18 & 51 \\
\hline Female & 17 & 34 \\
\hline \multicolumn{3}{|l|}{ Age } \\
\hline$<40$ years & 0 & 0 \\
\hline 40-50years & 2 & 6 \\
\hline $50-60$ years & 6 & 17 \\
\hline $60-70$ years & 17 & 49 \\
\hline $70-80$ years & 10 & 29 \\
\hline$>80$ years & 0 & 0 \\
\hline \multicolumn{3}{|l|}{ Employment Status } \\
\hline Employed/self employed & 11 & 31 \\
\hline Retired & 23 & 65 \\
\hline Student & 0 & 0 \\
\hline Unemployed & 0 & 0 \\
\hline Note added: semi-retired & 1 & 3 \\
\hline \multicolumn{3}{|l|}{ Educational level } \\
\hline School only & 15 & 44 \\
\hline $\begin{array}{l}\text { College/training } \\
\text { /apprenticeship }\end{array}$ & 11 & 32 \\
\hline University & 8 & 24 \\
\hline \multicolumn{3}{|l|}{ Site of online access } \\
\hline Home & 43 & 93 \\
\hline Work & 2 & 4 \\
\hline At a friend/relative's house & 1 & 2 \\
\hline Other & 0 & 0 \\
\hline
\end{tabular}

Number of virtual clinic follow-up appointments

\begin{tabular}{lrr}
1 & 26 & 54 \\
2 & 9 & 20 \\
3 & 4 & 9 \\
$>3$ & 8 & 17 \\
\hline Ethnicity & & \\
$\quad$ White British & 34 & 97 \\
\hline Other (Cornish) & 1 & 3 \\
\hline Difficulty communicating in English & \\
Yes & 1 & 3 \\
\hline No & 34 & 97 \\
\hline
\end{tabular}

*Percentages are calculated based on only those who responded to that question.

to be gained by streamlining services. Cautious initial patient selection was discussed and it was voiced that as few as $10 \%$ of patients may be suitable. However, there were concerns that with the recommended frequency of follow-up even with adopting a virtual clinic pathway 


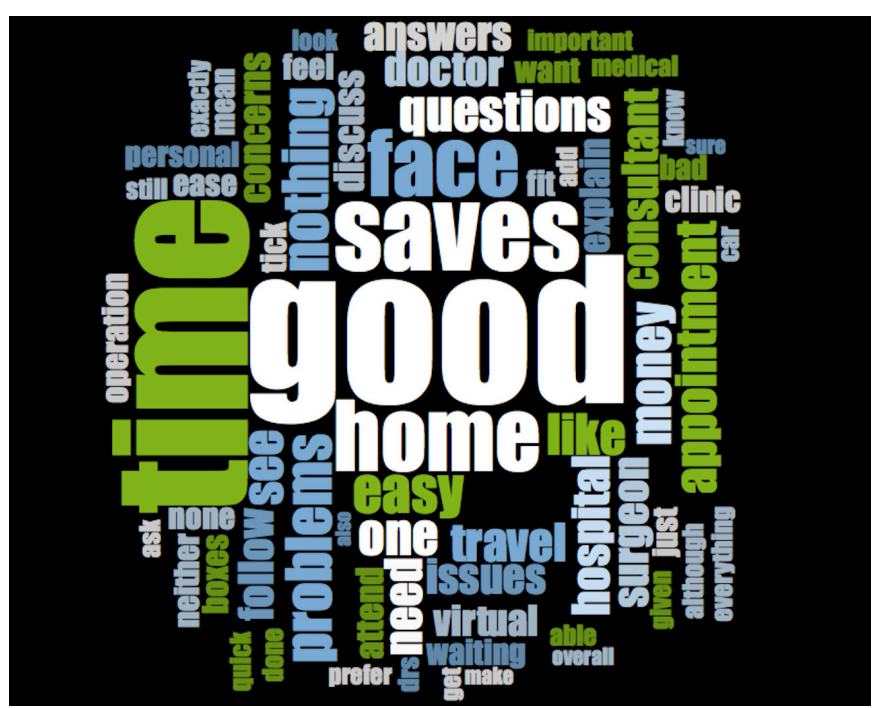

Figure 1 Word cloud of free text responses from patient questionnaire.

the workload may prove unmanageable. This workload perception could represent either a driver for, or barrier to, change.

There was also suggestion of another barrier to change within the department in the form of fear of conflict of interest:

"My underlying feeling was that because this was Dan's business there was a little bit of antagonism"

\section{Summary of main findings}

Patients found the virtual clinic relatively easy to engage with and some found it helpful in self-management. Preference for face-to-face appointments appears multi-factorial, possibly dependent on past experience and personal circumstances. Frustrations with the virtual clinic surrounded the restrictive nature of using scoring systems and concerns over how best to report concerns and deterioration between appointed review points. In order for the patient voice to be successfully heard it must be clear that the consultants have responded to any issue raised. Indeed, the key theme underpinning all the others is patient voice. Satisfaction is very closely tied to knowing you are heard and it is in times of deterioration that this is most crucial, while understanding the process and mastering the technology and other benefits simply facilitate this.

Consultants raised concerns about workload management and appropriate identification of suitable patients for the virtual clinic pathway. No harm was identified from the introduction of the virtual clinic, in either direct questioning in the interviews or through the free text question asking about difficulties and concerns in the questionnaire (see online supplementary appendix 4 Q15). However, a clear strategy is needed to balance the service needs with the needs of the patients to inform future implementation of virtual clinics.

\section{DISCUSSION}

\section{Strengths and limitations}

This is the first service evaluation that we are aware of which examines the experience and perceptions in moving from a traditional follow-up clinic to a virtual clinic pathway. The views of both patients and clinicians have been considered.

However, only patients who had used the virtual clinics pathway have been consulted. These patients had been screened for suitability and therefore were computer literate. However, many patients are not computer literate or do not have access to a computer. In addition, it is likely to be patients and staff who have engaged with the process that submit to interview and may not be a true representation of the wider population. Further it is not possible to elucidate which patients made comments in the questionnaire or whether they were later interviewed. Similarly, the sample is not large enough to allow for subgroup analysis of questionnaire results.

With interviewees being selected from those completing the questionnaire it has allowed for exploration in richness and depth including misunderstandings. However, all the data is from a similar time meaning that analysis of how attitudes evolve, as the service becomes established, remains unknown.

Only two clinicians were interviewed so the full spectrum of opinions is not captured. Other staff were impacted by the introduction of the virtual clinic pathway such as administrative staff and management but reporting on this is beyond the scope of this paper.

The context is that of a district general hospital covering a large rural area therefore, some benefits (eg, travel time saved) may not be generalisable to an urban setting.

Formal economic assessment is not addressed here. However, local commissioners have established an ongoing $£ 45$ tariff for virtual clinic appointments making the pathway sustainable. Between April 2017 and March 2018 there were a mean of 30 such appointments each month and the clinic remains ongoing.

\section{Comparison with existing literature}

National joint registry data indicates that the two most common reasons for revision in both hip and knee joint replacement are aseptic loosening and pain. ${ }^{13}$ Therefore, joint replacement follow-up processes need to encompass assessments that pick up both the symptomatic patient and those at risk of periprosthetic fracture as a result of osteolysis before they become symptomatic. ${ }^{2}$ Loosening and polyethylene wear presents between 7 and 20 years postoperatively in $72.6 \%$ of total hip replacement and aseptic loosening is the main reason for late revision in knee replacement. ${ }^{1415} \mathrm{~A}$ robust system is therefore required to follow-up patients in the longer term. A virtual clinic pathway allows for long-term monitoring, screening for symptomatic patients using web-based outcome scores and signs of asymptomatic loosening on interval X-ray films. Others have found a reduced administrative burden, high acceptance and potential cost savings 


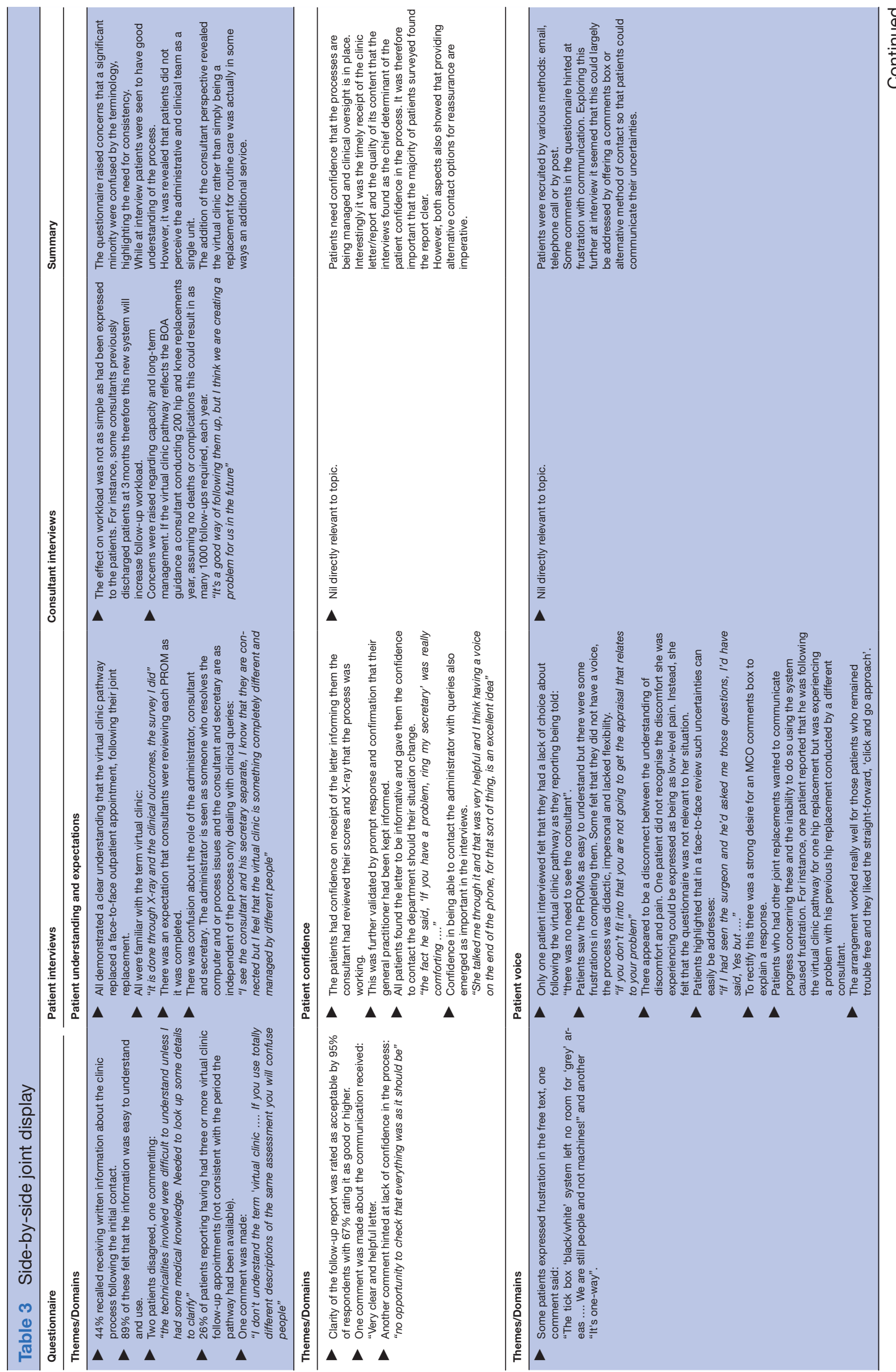

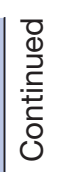




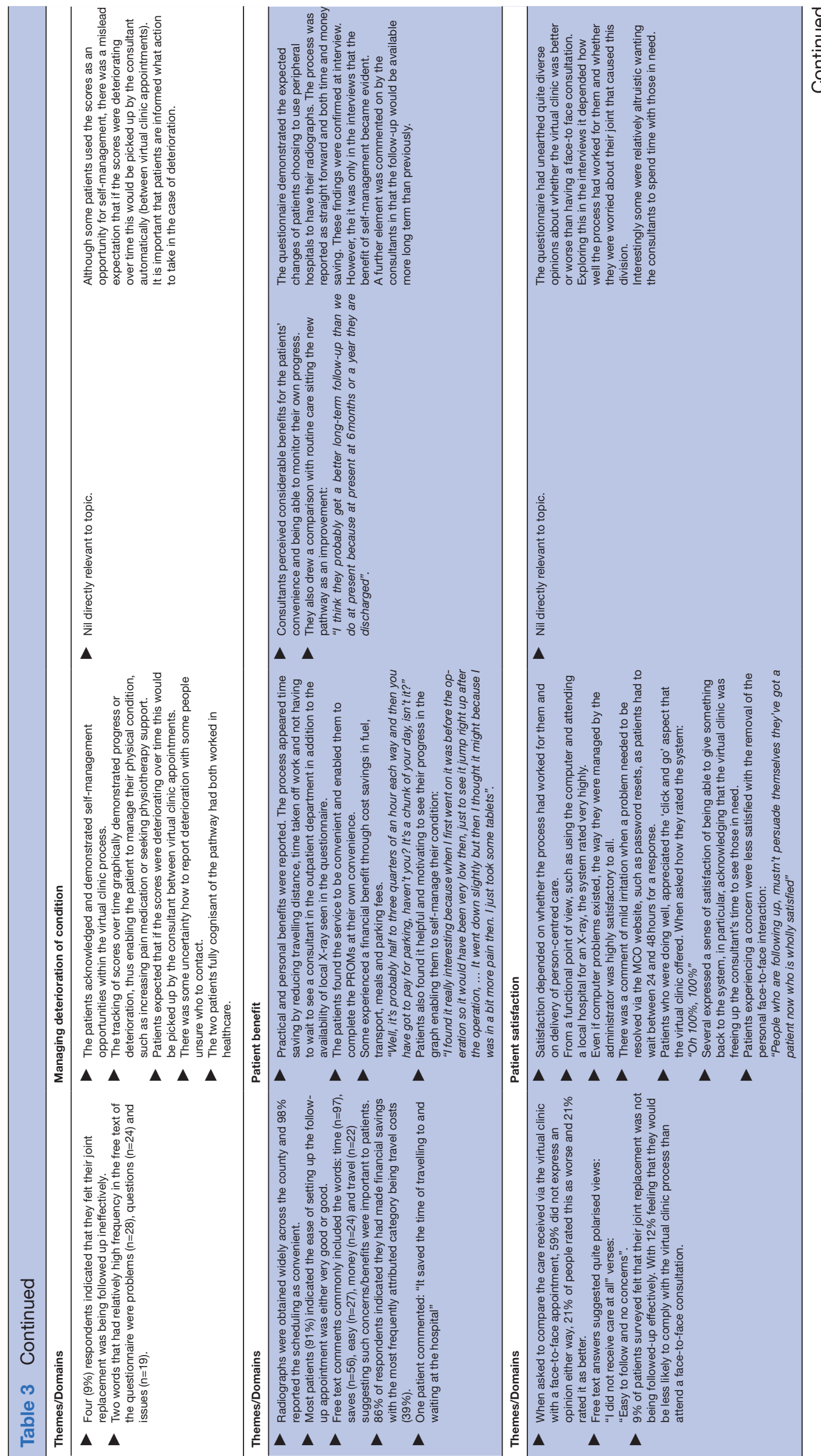




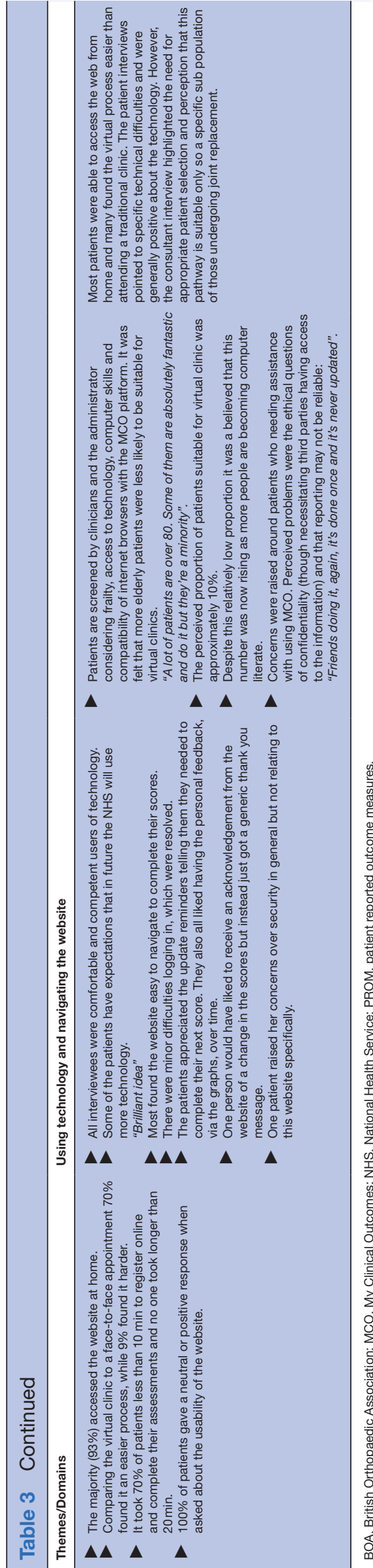

associated with electronically captured PROM data. ${ }^{16} 17$ Patients' positive experiences of the online platform and the cost savings they have personally experienced potentially facilitated our local transition.

The barriers to change in the more elderly patients were highlighted in the consultant interviews with concern more widely that those over 80 years will not be able to use a virtual clinic and may be lost to follow-up if their health or cognition deteriorate. However, internet use in elderly age groups is increasing and follow-up in patients over the age of 75 years at operation is not required long term. ${ }^{5}$ Patients having a joint replacement over the age of 70 years have a lifetime risk of requiring revision of between $1 \%$ and $6 \%$ for hip and knee, respectively, compared with $29.6 \%$ and $35 \%$ in men aged $50-54$ years. ${ }^{18}$ In the more elderly, frailer group of patients the symptomatic thresholds for revision surgery are likely to be higher reflected in less stringent requirements for follow-up.

Two studies have examined the introduction of virtual clinics for joint replacement follow-up using radiographs and web based questionnaires. ${ }^{2}$ A Canadian virtual clinic pilot in a mixed cohort of 40 patients with a mean age of 40 years undergoing hip and knee replacement found that men were significantly more likely to agree to participate than women $(p=0.010)$ and that those having hip replacements were less likely to engage than those having knee replacements $(\mathrm{p}=0.019)$. Patients experienced problems logging on (22.5\%) and with case sensitive passwords $(7.5 \%) .{ }^{19}$ Interestingly radiograph assessment was found to be significantly more thorough when performed independently of a face-to-face appointment. ${ }^{19}$ By working closely with $\mathrm{MCO}$ in the early stages these electronic issues proved less of an issue in our cohort helping to facilitate the change.

In the same region of Canada 256 patients with a mean age of 68 years (closer to the 'typical' patient) a hip or knee replacement were randomised to either virtual follow-up or usual care. In addition to completing PROMs and undergoing X-ray films patients were asked two questions. (1) Do you have any pain or symptoms in your replacement joint? (2) Do you have any problems in your other hip or knee? A face-to-face appointment was provided if patients answered 'yes' to either question. Fourteen per cent of those who declined to take part did so because they preferred to have a face-to-face consultation; $10 \%$ declined based on being symptomatic. Satisfaction while good was not as high as in the routine care group (although this was not quantified). ${ }^{20}$

Our interviews also found satisfied patients who missed the personal touch of a face-to-face interaction. This may be related to the wider, still not fully appreciated, interactions of emotional and physical support affecting patient outcomes. $^{2}$

Dual assessment of 599 patients in England by a faceto-face Arthroplasty Care Practitioner appointment and by remote surgeon review of X-ray film and paper-based PROMs showed good agreement between the outcomes. 
However, some cases of 'potential problems' were not identified by the remote assessment. ${ }^{21}$ Both the patients and staff interviewed locally agreed with a recent review, that those with symptoms must have easy access to faceto-face review, at whatever stage these symptoms occur. ${ }^{2}$ Virtual clinics potentially free up face-to-face clinic capacity to see those patients who need it most.

\section{CONCLUSION}

Although barriers to change were identified and areas of the process require refinement, the virtual clinic process appears to be well accepted by at least some selected patients and consultant clinicians. The 'click and go' format seems most suited to those patients who are not experiencing problems with their joint replacement. In developing such systems, it must be recognised that people value the personal interaction of face-to-face appointments and that clear pathways of communication are essential, especially when a problem or concern is identified. These findings align with the intention of virtual clinics to provide cost effective follow-up and faceto-face capacity for those patients that need it.

Contributors DHW clinically oversaw the study design and implementation of the new virtual clinic. JP and JW conducted the interviews and initial analysis. RJP undertook the wider analysis and wrote the paper with JP, JW and DHW all making contributions to the drafts and approving the final version.

Funding Shine funding from the Health Foundation. MCO provided their platform free of charge to the Trust.

Competing interests DHW is co-founder of MCO. There are no other competing interests.

Patient consent for publication Not required.

Provenance and peer review Not commissioned; externally peer reviewed.

Data sharing statement No additional data are available.

Open access This is an open access article distributed in accordance with the Creative Commons Attribution Non Commercial (CC BY-NC 4.0) license, which permits others to distribute, remix, adapt, build upon this work non-commercially, and license their derivative works on different terms, provided the original work is properly cited, appropriate credit is given, any changes made indicated, and the use is non-commercial. See: http://creativecommons.org/licenses/by-nc/4.0/.

\section{REFERENCES}

1. National Institute for Health and Clinical Excellence. NICE guideline: Hip, knee and shoulder joint replacement draft scope for consultation. 2018 https://www.nice.org.uk/guidance/GID-NG10084/ documents/draft-scope

2. Lovelock TM, Broughton NS. Follow-up after arthroplasty of the hip and knee: are we over-servicing or under-caring? Bone Joint $J$ 2018;100-B:6-10.

3. Cross M, Smith E, Hoy D, et al. The global burden of hip and knee osteoarthritis: estimates from the global burden of disease 2010 study. Ann Rheum Dis 2014;73:1323-30.

4. Kurtz S, Ong K, Lau E, et al. Projections of primary and revision hip and knee arthroplasty in the United States from 2005 to 2030. J Bone Joint Surg Am 2007;89:780-5.

5. British Orthopaedic Association. Pain arising from the hip in adults - Commissioning guide. 2014 https://www.boa.ac.uk/pro-practice/ pain-arising-from-the-hip-in-adults-commissioning-guide/

6. Guide C. British Orthopaedic Association. Painful osteoarthritis of the knee. 2015 http://www.boa.ac.uk/pro-practice/commissioningguide-painful-osteoarthritis-knee/

7. British Hip Society. Primary total hip replacement: a guide to good practice. 2012 https://www.britishhipsociety.com

8. Greenhalgh T, Vijayaraghavan S, Wherton J, et al. Virtual online consultations: advantages and limitations (VOCAL) study. BMJ Open 2016;6:e009388.

9. Griffiths-Jones W, Norton MR, Fern ED, et al. The Equivalence of Remote Electronic and Paper Patient Reported Outcome (PRO) Collection. J Arthroplasty 2014;29:2136-9.

10. Monitor Progress. My Clinical Outcomes. http://www. myclinicaloutcomes.com

11. SurveyMonkey Inc. San Mateo, California, USA. www.surveymonkey. com

12. Braun V, Clarke V. Using thematic analysis in psychology. Qual Res Psychol 2006;3:77-101.

13. The NJR Editorial Board. 14th Annual Report 2017. National Joint Registry for England, Wales, Northern Ireland and the Isle of Man. 2017 http://www.njrreports.org.uk

14. Wroblewski BM, Siney PD, Fleming PA. Charnley low-friction arthroplasty: survival patterns to 38 years. J Bone Joint Surg $\mathrm{Br}$ 2007;89:1015-8.

15. Khan M, Osman K, Green G, et al. The epidemiology of failure in total knee arthroplasty: avoiding your next revision. Bone Joint J 2016;98B:105-12.

16. Coons SJ, Eremenco S, Lundy JJ, et al. PRO) Data Electronically: The Past, Present, and Promise of ePRO measurement in clinical trials. The Patient 2015;8:301-9.

17. Jayaram PR, Bhattacharyya R, Jenkins PJ, et al. A new "virtual" patient pathway for the management of radial head and neck fractures. J Shoulder Elbow Surg 2014;23:297-301.

18. Bayliss LE, Culliford D, Monk AP, et al. The effect of patient age at intervention on risk of implant revision after total replacement of the hip or knee: a population-based cohort study. The Lancet 2017;389:1424-30.

19. Wood G, Naudie D, MacDonald S, et al. An electronic clinic for arthroplasty follow-up: a pilot study. Can J Surg 2011;54:381-6.

20. Marsh JD, Bryant DM, MacDonald SJ, et al. Feasibility, effectiveness and costs associated with a web-based followup assessment following total joint arthroplasty. J Arthroplasty 2014;29:1723-8.

21. Kingsbury SR, Dube B, Thomas CM, et al. Is a questionnaire and radiograph-based follow-up model for patients with primary hip and knee arthroplasty a viable alternative to traditional regular outpatient follow-up clinic? Bone Joint J 2016;98-B:201-8. 